\title{
Mapping Resistance Quantitative Trait Loci for Three Foliar Diseases in a Maize Recombinant Inbred Line Population-Evidence for Multiple Disease Resistance?
}

\author{
John C. Zwonitzer, Nathan D. Coles, Matthew D. Krakowsky, Consuelo Arellano, James B. Holland, \\ Michael D. McMullen, Richard C. Pratt, and Peter J. Balint-Kurti
}

First author: Department of Plant Pathology, and second author: Department of Crop Science, North Carolina State University, Raleigh 27695; third author: United States Department of Agriculture-Agricultural Research Service (USDA-ARS) and Department of Crop Science, North Carolina State University; fourth author: Department of Statistics, North Carolina State University; fifth author: United States Department of Agriculture-Agricultural Research Service (USDA-ARS) and Department of Crop Science, North Carolina State University; sixth author, University of Missouri, 204 Curtis Hall, Columbia 65211; seventh author: Department of Horticulture and Crop Science, The Ohio State University-Ohio Agricultural Research and Development Center, 1680 Madison Avenue, Wooster 44691; and eighth author: USDA-ARS Plant Science Research Unit and Department of Plant Pathology, North Carolina State University. Accepted for publication 13 September 2009.

\section{ABSTRACT}

Zwonitzer, J. C., Coles, N. D., Krakowsky, M. D., Arellano, C., Holland, J. B., McMullen, M. D., Pratt, R. C., and Balint-Kurti, P. J. 2010. Mapping resistance quantitative trait loci for three foliar diseases in a maize recombinant inbred line population-evidence for multiple disease resistance? Phytopathology 100:72-79.

Southern leaf blight (SLB), gray leaf spot (GLS), and northern leaf blight (NLB) are all important foliar diseases impacting maize production. The objectives of this study were to identify quantitative trait loci (QTL) for resistance to these diseases in a maize recombinant inbred line (RIL) population derived from a cross between maize lines Ki14 and $\mathrm{B} 73$, and to evaluate the evidence for the presence genes or loci conferring multiple disease resistance (MDR). Each disease was scored in multiple separate trials. Highly significant correlations between the resistances and the three diseases were found. The highest correlation was identified between SLB and GLS resistance $(r=0.62)$. Correlations between resistance to each of the diseases and time to flowering were also highly significant. Nine, eight, and six QTL were identified for SLB, GLS, and NLB resistance, respectively. QTL for all three diseases colocalized in bin 1.06, while QTL colocalizing for two of the three diseases were identified in bins 1.08 to $1.09,2.02 / 2.03,3.04 / 3.05,8.05$, and 10.05. QTL for time to flowering were also identified at four of these six loci (bins 1.06, 3.04/3.05, 8.05, and 10.05). No disease resistance QTL was identified at the largest-effect QTL for flowering time in bin 10.03 .
Most maize (Zea mays L. subsp. mays) disease resistance is quantitative rather than qualitative in nature (83). Qualitative disease resistance is generally controlled by one gene or a few genes with major effects, whereas quantitative disease resistance (QDR) is generally controlled by many minor genes $(61,75)$. Although rapid progress has been made in recent years in the genetic characterization of qualitative disease resistance (11), progress in the understanding of the genetic and physiological processes underlying QDR has been limited due to their complexity and incomplete and variable expression $(29,40,85)$.

Multiple disease resistance (MDR), in which the same locus conditions resistance to multiple pathogens, is both practically and conceptually important and yet is also poorly understood. Limited evidence is available regarding quantitative trait loci (QTL) conditioning MDR. The detection of clusters of QTL conferring resistance to multiple diseases is consistent with but does

Corresponding author: P. Balint-Kurti;

E-mail address: Peter.Balint-Kurti@ars.usda.gov

* The $\boldsymbol{e}$-Xtra logo stands for "electronic extra" and indicates that the online version contains a figure showing the Ki14 $\times$ B73 linkage map of the 10 maize chromosomes and the positions of the QTL identified in this study.

doi:10.1094/PHYTO-100-1-0072

This article is in the public domain and not copyrightable. It may be freely reprinted with customary crediting of the source. The American Phytopathological Society, 2010. not prove the hypothesis that MDR genes are present in plants $(83,84)$. More direct evidence for MDR is the observation of pleiotropic effects on multiple diseases shown with some induced gene mutations $(17,18,23,54)$. Mitchell-Olds (53) studied genetic correlations among levels of disease resistance of Brassica rapa to three fungal pathogens: Peronospora parasitica, Albugo candida, and Leptosphaeria maculans. They reported heritable genetic variation for resistance to all three pathogens and positive, statistically significant genetic correlations between resistance to L. maculans and P. parasitica in populations in which selection was directed at only one of the pathogens. Recently, Balint-Kurti et al. (6) identified highly significant correlations between resistances to southern leaf blight (SLB), gray leaf spot (GLS), and northern leaf blight (NLB) in the maize intermated B73 $\times$ Mo17 (IBM) population (43), although they did not detect any disease resistance QTL associated with resistance to all three diseases. Analysis of complex trait inheritance in single population can only provide a partial understanding of its genetic architecture, however, because of the potential genetic heterogeneity of such traits across diverse germplasm. Therefore, a robust understanding of the genetic architecture of MDR requires its analysis in additional mapping populations.

SLB, causal agent Cochliobolus heterostrophus (Drechsler) Drechsler (anamorph = Bipolaris maydis (Y. Nisik. \& C. Miyake) Shoemaker); GLS, caused by Cercospora zeae-maydis (Tehon and E. Y. Daniels); and NLB, causal agent Setosphaeria turcica (Luttr.) K. J. Leonard \& Suggs (anamorph Exserohilum turcicum 
(Pass.) K. J. Leonard \& Suggs), are foliar, substantially necrotrophic, fungal pathogens of maize. All three pathogens are ascomycete fungi in the class Dothideomycetes and share some similar pathogenesis characteristics $(10,38)$. For all these diseases, infection is initiated when spores land on the leaf surface, germinate, and penetrate either directly through the stomata or the leaf cuticle and epidermis. S. turcica grows intracellularly in the leaf while Cochliobolus heterostrophus and Cercospora zeaemaydis grow intercellularly during initial infection. The latent periods (period of time from infection to sporulation) for the three fungi vary from a few days for Cochliobolus heterostrophus to $\approx 2$ weeks for $S$. turcica and up to 3 weeks for Cercospora zeaemaydis $(10,38)$. It seems likely that loci associated with regulating aspects of the parts of the pathogenesis process shared by two or more of these pathogens may be detected as MDR QTL. This hypothesis was tested in this study.

SLB is a widespread disease with the potential to cause yield losses in hot and humid tropical and subtropical regions, such as the southeastern United States, parts of India, Africa, Latin America, and Southern Europe (82). Resistance to SLB is quantitatively inherited and the gene action is primarily additive or partially dominant $(14,34-36,46,47,55,71)$. Under experimental conditions, yield losses as high as 38 to $46 \%$ have been observed in maize inoculated with SLB $(15,28)$. However, losses of this magnitude are rare, because most hybrids have some level of quantitative resistance.

GLS is one of the most significant yield-limiting diseases of maize worldwide. It has greatly increased in importance and geographical distribution in the last 25 years, primarily as a result of moves toward conservation tillage and no-till practices, which allows GLS inoculum to overwinter in debris on the soil surface $(1,42,56,57)$. This disease is a serious threat in the Eastern United States and sub-Saharan Africa as well as in the more temperate and humid regions of Mexico, Central and South America, Europe, and Asia $(49,79,82)$. In most cases, GLS resistance is moderately to highly heritable and additive in nature $(30,37,72)$.

NLB can cause extensive disease in areas where temperatures are moderate $\left(15\right.$ to $25^{\circ} \mathrm{C}$ ) during the growing season (45). Severe NLB infection prior to flowering may cause $>50 \%$ total yield loss $(59,70)$. Historically both, qualitative and quantitative disease resistance have been important for controlling NLB. $(22,82)$.

The objectives of this study were to map QTL associated with SLB, GLS, and NLB resistance in a Ki14 × B73 (KB) recombinant inbred line (RIL) population and to identify QTL that potentially confer MDR. Disease resistance has been shown in a number of studies to be correlated with time to maturity (83). Therefore, QTL for time to anthesis were also mapped to see whether they colocalized with any disease resistance QTL.

\section{MATERIALS AND METHODS}

Parents and RIL development. A RIL population was developed from a cross between two maize inbreds, Ki14 and B73. The parents are of tropical and U.S. Corn Belt origin, respectively. Ki14 (previously designated KUI14) was released in 1975 from Kasetsart University in Thailand. It was developed from Suwan-1 (S) C4, a high-yielding cultivar which provided resistance to infection by Peronosclerospora sorghi (casual agent of downy-mildew) $(67,69)$. The Suwan-1 population was initially developed from a composite pedigree of West Indian, Mexican, and Central and South American lines, U.S. dents, P. sorghiresistant lines, and other germplasm. Ki14 is more resistant than B73 to SLB, NLB, and GLS.

B73 was developed at Iowa State University $(62,73)$. Although B73 is susceptible to many diseases and insects, its high yield potential $(2,26)$ and excellent seed production attributes led to its widespread use in the development of public- (32) and privatesector inbred lines (52).
Individual $\mathrm{F}_{2}$ generation plants from a $\mathrm{KB}$ cross were selfed for five generations to produce $\mathrm{F}_{5: 6}$ seed. These lines were designated as RIL lines KB001 to KB135. Then, 117 of the RILs were selfpollinated in Ohio to produce $\mathrm{F}_{6: 7}$ seed. The lines were again increased by self-pollination of several plants within each line and the seed was bulked to produce $\mathrm{F}_{6: 8}$ lines. The $\mathrm{F}_{6: 8}$ RILs (henceforth called the KB population) were used for screening SLB, GLS, and NLB in this study. All 117 lines were assessed for each disease although, ultimately, only 109 of these lines were suitable for use in QTL analysis (see below).

Field trials. Disease screening trials for SLB were performed in five environments: at Clayton, NC in 2004, 2005, and 2006 (CL04, CL05, and CL06); at Tifton, GA in 2005 (GA05); and one environment in Wooster, OH in 2004 (KING04), with two replications at each environment. Each trial was performed using a randomized complete block design. CL04, CL05, CL06, and GA05 plots were planted as single rows $2 \mathrm{~m}$ in length, with $0.97 \mathrm{~m}$ between rows and a $0.6-\mathrm{m}$ alley at the end of each plot. Twelve seeds per entry were planted in each plot and the rows were not thinned. KING04 plots were planted as single rows $3.04 \mathrm{~m}$ in length, with $0.76 \mathrm{~m}$ between rows and a $0.46-\mathrm{m}$ alley at the end of each plot. Fifteen seeds per entry were planted in each plot and rows were not thinned.

SLB inoculum for the field disease screening experiments was prepared as previously described (21), and rows were inoculated at the four- to six-leaf stage by placing $\approx 20$ grains of Cochliobolus heterostrophus race O, isolate 2-16Bm-infested (Sorghum bicolor M.) grain in the leaf whorl $(20,21)$. Immediately after inoculation in the late afternoon, the field was irrigated by overhead irrigation to provide free moisture to initiate fungal growth.

Disease screening trials for GLS were performed in six environments: at Andrews, NC in 2004 and 2005 (ANDW04 and ANDW05); at Salisbury, NC in 2006 (SBRY06); and two environments in 2004 and one environment in 2005 at Wooster, OH (FRY04, FRY05, and KING04), with two replications at each environment. Each trial conducted in North Carolina was performed using a randomized complete block design. Plots were planted as single rows $4 \mathrm{~m}$ in length, with $0.97 \mathrm{~m}$ between rows and a $0.6-\mathrm{m}$ alley at the end of each plot. Fifteen seeds per entry were planted in each plot and the rows were not thinned. Ohio trials were planted as single rows $3.04 \mathrm{~m}$ in length, with $0.76 \mathrm{~m}$ between rows and a $0.46-\mathrm{m}$ alley at the end of each plot. The FRY04 and KING04 environments were inoculated using isolates collected in the field in 2003. The inoculum was applied by placing several infested sorghum kernels in the whorl of the maize plants. Naturally occurring GLS inoculum was used for field disease screening trials for ANDW04, ANDW05, FRY05, and SBRY06. These four trials were no-till planted into corn residue from the previous year.

NLB disease screening trials were performed at six environments: at Clayton, NC in 2006 (CL06); and two environments in 2004 and one environment in each of 2005, 2006 and 2007 at Wooster, OH (FRY04, KING04, SHFTR05, SHFTR06, and OARDC07), with two replications planted at each environment, except for OARDC07, with one replication. Trials for CL06, FRY04, and KING04 were planted as described above. All other plots at Ohio were planted as single rows $4.6 \mathrm{~m}$ in length, with $0.76 \mathrm{~m}$ between rows and a $0.61-\mathrm{m}$ alley at the end of each plot.

The CL06 NLB inoculation was conducted using infected sorghum grain produced in the same way as the SLB inoculum (21). Rows were inoculated at the four- to six-leaf stage by placing $\approx 20$ grains of NLB inoculum (sorghum grain culture) in the leaf whorl. The NLB inoculum contained a mixture of isolates with various race-specificities (Setosphaeria turcica race 0, race 1 , race 23 , and race $23 \mathrm{~N}$ ). The remaining five environments were inoculated using the following procedures. E. turcicum inoculum was produced from an isolate obtained from infected maize leaves from Licking County, $\mathrm{OH}$. Aseptic cultures were produced from 
sporulating conidia and maintained in petri plates containing lactose casein hydrolysate agar (37.5 $\mathrm{g}$ of lactose, $3 \mathrm{~g}$ of casein hydrolysate, $1 \mathrm{~g}$ of $\mathrm{KH}_{2} \mathrm{PO}_{4}, 5 \mathrm{~g}$ of $\mathrm{MgSO}_{4}, 2 \mathrm{ml}$ of microelements, and $15 \mathrm{~g}$ of agar dissolved in 1 liter of deionized water). Colonized media sections from the culture were placed onto sorghum kernels as described above. Cultures were subsequently handled according to the protocol described by Hakiza et al. (31). Before inoculation, race-specific virulence of the isolates was established by inoculating known differentials of maize: inbred lines H4460, H4460Ht1, H4460Ht3, A619, A619Ht and A619Ht2 grown in the greenhouse at the Ohio Agricultural Research and Development Center (OARDC). Based on the specific reactions of these differentials, isolates were confirmed to be race 1 . Neither Ki14 nor B73 have any known $H t$ genes and, therefore, are assumed to have no qualitative resistance to any of the NLB isolates used. Plots were inoculated twice by placing several kernels of NLB inoculum (sorghum grain culture) in the leaf whorl at the five-leaf stage and then again at the seven-leaf stage.

Rating of field trials. All field trials were scored for resistance on a per-plot basis using a 1-to-9 scale in increments of 0.5 , with $1=$ symptomless, $3=$ small lesions on the ear leaf, $5=$ confluent necrosis on the ear leaf, $7=$ the ear leaf and the leaf above it almost completely dead, and $9=$ completely dead. The field trials in Clayton, Salisbury, and Andrews were rated multiple times at intervals of 10 days to 2 weeks, while the trials in Ohio were only rated once, late during the growing season after flowering but before leaf senescence. Because more than two disease ratings were taken in some environments the weighted mean disease (WMD) was calculated as previously described (8). WMD rating values were calculated for each replication in each environment by taking the average value of two consecutive ratings and multiplying by the number of days between the ratings. Values were then summed over all the intervals and divided by the number of days between the first and last evaluations. WMD is equivalent to standardized area under the disease progress curve (sAUDPC) $(16,68)$.

Days to anthesis (DTA) was measured for the SLB CL04, CL05, and CL06 trials and for the GLS ANDW05 trial. A row was deemed to have reached anthesis when half the plants in the row were shedding pollen. Because of the strong influence of temperature on DTA, measurements were converted to growing degree days to anthesis (GDDTA) following McMaster and Wilhelm (50), with 10 and $30^{\circ} \mathrm{C}$ as minimum and maximum temperatures, respectively. Growing degree day is a measurement of the cumulative average daily heat units that an experimental plot receives from the time of planting

DNA extraction and molecular markers. For simplesequence repeat (SSR) analyses, DNA was extracted using a modified Saghai-Maroof et al. (63) cetyltrimethylammonium bromide extraction procedure previously described (87). Two parents, B73 and Ki14, and 117 lines from the KB population were screened with $\approx 200$ SSR primer pairs and 1,536 SNP markers to identify polymorphic markers for the KB population. Amplification of SSRs on the parents and the KB population were screened as previously described (66). SSR detection was performed as described by Robertson-Hoyt et al. (60). SNP genotype data were generated using the Illumina Golden Gate genotyping assay (27). Of the initial 1,536 SNPs, 771 SNPs failed, were homozygous for the KB population, or showed $>30 \%$ heterozygosity, resulting in data available for 765 SNPs. In addition, 106 polymorphic SSR markers were identified. Based on the genotypic data, eight lines were identified as likely or possible outcrosses and were removed from the data set. Therefore, the statistical analyses, linkage mapping, and QTL mapping were performed using 109 RILs.

Construction of linkage map. JoinMap 3.0 (76) was used to estimate locus orders, identify linkage groups, and transform estimated recombination frequencies to centimorgans using the Haldane mapping function. Linkage mapping was performed on a composite map produced by combining the four mapping populations, including the KB population, as previously described (25). In addition to the KB population, the other three RIL populations used to produce the linkage map were developed by crossing B73 × CML254, CML254 × B97, and B97 × Ki14. The KB linkage map (25) was produced by combining the SSR data from each of the four mapping populations, plus SNP data from the two populations which had B73 as a parent (i.e., the KB population and B73 $\times$ CML254), because these were the only populations from that study with available SNP genotypic data at the time of our analysis. In regions where the marker order of the KB map differed greatly from the intermated IBM reference maps (http://www.maizegdb.org), the MAPMAKER/EXP $3.0(41,48)$ COMPARE command was used to finalize marker order. The final linkage map produced by MAPMAKER/EXP agreed closely with the order defined by the commonly used IBM2 2005 Neighbors (IBM 2005) reference map (http://www.maizegdb.org).

Statistical analyses. Genotype least square means (LSM) for SLB WMD, GLS WMD, and NLB WMD were estimated across

TABLE 2. Pearson correlation coefficients between least square means for southern leaf blight measured at five environments: at Clayton, NC in 2004, 2005, and 2006 (CL04, CL05, and CL06); at Tifton, GA in 2005 (GA05); and at Wooster, OH in 2004 (KING04)

\begin{tabular}{lllll}
\hline Location & \multicolumn{1}{c}{ CL05 } & \multicolumn{1}{c}{ CL06 } & \multicolumn{1}{c}{ GA05 } & \multicolumn{1}{c}{ KING04 } \\
\hline CL04 & $r=0.88$ & $r=0.85$ & $r=0.80$ & $r=0.36$ \\
& $P<0.0001$ & $P<0.0001$ & $P<0.0001$ & $P=0.002$ \\
CL05 & $\ldots$ & $r=0.89$ & $r=0.82$ & $r=0.37$ \\
& & $P<0.0001$ & $P<0.0001$ & $P=0.001$ \\
CL06 & $\ldots$ & $\ldots$ & $r=0.83$ & $r=0.28$ \\
& & & $P<0.0001$ & $P=0.024$ \\
GA05 & $\ldots$ & $\ldots$ & $\ldots$ & $r=0.31$ \\
& & & & $P=0.011$ \\
\hline
\end{tabular}

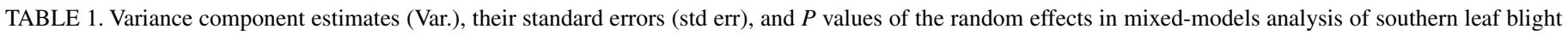

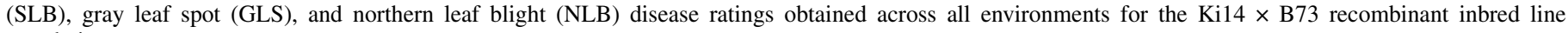
population $^{\mathrm{a}}$

\begin{tabular}{|c|c|c|c|c|c|c|}
\hline \multirow[b]{2}{*}{ Random factor $^{\mathrm{b}}$} & \multicolumn{2}{|c|}{ SLB } & \multicolumn{2}{|c|}{ GLS } & \multicolumn{2}{|c|}{ NLB } \\
\hline & Var. (SE) & $P$ value & Var. (SE) & $P$ value & Var. (SE) & $P$ value \\
\hline Env & $0.57(0.42)$ & 0.0002 & $0.3(0.2)$ & 0.0001 & $2.11(1.36)$ & $<0.0001$ \\
\hline Rep (Env) & $0.03(0.02)$ & $<0.0001$ & $0.02(0.02)$ & $<0.0001$ & $0.04(0.04)$ & 0.0027 \\
\hline Line & $0.45(0.07)$ & $<0.0001$ & $0.27(0.05)$ & $<0.0001$ & $0.44(0.09)$ & $<0.0001$ \\
\hline Env $\times$ Line & $0.16(0.03)$ & $<0.0001$ & $0.22(0.03)$ & $<0.0001$ & $0.38(0.08)$ & 0.0001 \\
\hline Error & $0.29(0.02)$ & $\ldots$ & $0.35(0.02)$ & $\ldots$ & $1.25(0.08)$ & $\ldots$ \\
\hline
\end{tabular}

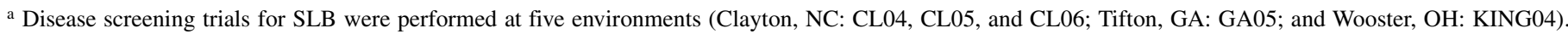

Disease screening trials for GLS were performed at six environments (Andrews, NC: ANDW04 and ANDW05; Salisbury, NC: SBRY06; and Wooster, OH:FRY04, FRY05, and KING04). NLB disease screening trials were performed at six environments (Clayton, NC: CL06; and Wooster, OH: FRY04, KING04, SHFTR05, SHFTR06, and OARDC07).

${ }^{\mathrm{b}} \mathrm{Env}=$ environment and Rep $=$ replication. 
all environments for each disease and were used as the trait values for QTL analysis. In addition, LSM for GDDTA were calculated across the four environments in which this trait was measured (see above). LSM were calculated using PROC MIXED in SAS (version 9.1.3; SAS Institute, Cary, NC) with line as a fixed-effect factor and all other factors (environment, environment-line, and replication within environment) considered as random effects. The PROC CORR procedure in SAS was used to calculate all phenotypic correlations. Estimates of heritability, environment, replication within environment, line, and environment-line interaction were considered random in PROC MIXED (33). Significance of random-effect variation was tested using the type III $F$ test $($ PROC MIXED, method = type3).

QTL detection and estimation. In the current study, detected QTL are reported for each SLB, GLS, NLB, and GDDTA, with all environments combined for each disease. QTL Cartographer version 2.5 (78) was used for QTL mapping. Composite interval mapping (CIM) was used to create an initial model for each disease separately. CIM was performed using a 1.0-centimorgan (cM) walk speed, a window size of $10 \mathrm{cM}$, and the CIM Model 6 with forward and backward regression, using a probability of 0.05 to include or exclude a QTL from the model.

Multiple interval mapping (MIM) was initiated from the CIM models using a logarithm-of-odds (LOD) threshold of 2.6 and a minimum distance of $10 \mathrm{cM}$ between QTL. These values were chosen to reduce the number of QTL used in the initial model, because the default settings included too many QTL in the initial model. The search for the best MIM model was completed in an iterative, stepwise manner, searching for new QTL, testing for their significance after each cycle of searching for new QTL, and optimizing QTL positions when new QTL were added to the model. New models were accepted if they decreased the Bayesian information criterion (BIC) (58). Use of the BIC is the best choice if the experimental objectives are to deduce genetic parameters such as the number of QTL (86). Using the BIC gives preference to models with higher likelihoods; however, it also includes a penalty for each additional parameter that is added to the model to prevent overfitting the model $(4,60,74)$. When no additional QTL could be added to the model while decreasing the BIC, each pair of QTL in the model was tested for epistatic interactions. An additional approach used to prevent overfitting QTL models was to exclude models in which the proportion of the total phenotypic variation accounted for by the QTL exceeded the entry mean heritability. If the model was overfit, the QTL with the smallest effect was dropped from the model and the effects of the remaining QTL were reestimated. Additive effects and QTL interactions were reported when the LOD score was $>2.0$. These threshold values were set to limit the number of QTL reported such that several QTL of very small effect identified in the final MIM analysis were not reported.

\section{RESULTS}

Phenotypic ratings. The variance components for all randomeffect factors (environment, replication within environment, line, and environment-line interaction) for the three diseases were significantly different from zero (Table 1). The high level of variation associated with environment likely reflects the fact that each disease was assessed in relatively diverse environments in northern Ohio and in central North Carolina. Pairwise Pearson correlations of SLB WMD scores were significant between all pairs of environments of 0.28 to 0.89 (Table 2). The correlations between CL04, CL05, CL06, and GA05 for SLB were highly significant $(P<0.0001)$, with correlation coefficients of 0.80 to 0.89 . Pearson correlations of GLS WMD scores were highly significant between all but one pair of environments, FRY04 and SBRY06 (Table 3). Pairwise NLB WMD Pearson correlation coefficients ranged from highly significant (SHFTR05 and SHFTR06, $r=0.56$ and $P<0.0001)$ to not significant (OARDC07-KING04, $r=0.1, P=0.1881$ ) (Table 4) but most pairwise correlations ( 10 of 15 ) were significant to at least the $P<$ 0.05 level. Correlations between overall LSM of the three diseases were statistically significant; the highest correlation was identified between SLB and GLS $(r=0.62, P<0.0001)$ (Table 5). The entry mean heritability across all environments was $0.85 \pm$ 0.02 for SLB, $0.75 \pm 0.04$ for GLS, and $0.67 \pm 0.05$ for NLB.

In addition to disease resistance ratings, GDDTA was measured in the SLB CL04, CL05 and CL06 trials and for the GLS ANDW05 trial. The heritability for GDDTA across these four environments was $0.68 \pm 0.04$. Pairwise correlations between overall LSM for the three diseases and GDDTA ranged from -0.24 to -0.51 and were statistically significant (Table 5). In other

TABLE 5. Pearson correlation coefficients between overall least square means for three diseases: southern leaf blight (SLB), gray leaf spot (GLS) northern leaf blight (NLB), and growing degree days to anthesis (GDDTA)

\begin{tabular}{llll}
\hline Disease & \multicolumn{1}{c}{ GLS } & \multicolumn{1}{c}{ NLB } & GDDTA \\
\hline SLB & $r=0.62$ & $r=0.25$ & $r=-0.51$ \\
& $P<0.0001$ & $P=0.0075$ & $P<0.0001$ \\
GLS & $\ldots$ & $r=0.32$ & $r=-0.47$ \\
& & $P=0.0005$ & $P<0.0001$ \\
NLB & $\cdots$ & $\cdots$ & $r=-0.24$ \\
& & & $P=0.012$ \\
\hline
\end{tabular}

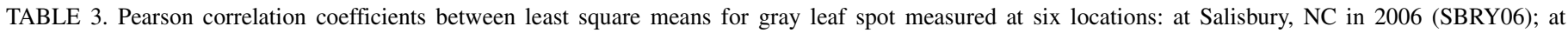

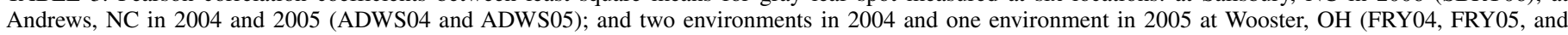
KING04)

\begin{tabular}{|c|c|c|c|c|c|}
\hline Location & ADWS04 & ADWS05 & FRY04 & FRY05 & KING04 \\
\hline SBRY06 & $r=0.46, P<0.0001$ & $r=0.59, P<0.0001$ & $r=0.05, P=0.6694$ & $r=0.43, P<0.0001$ & $r=0.31, P=0.0085$ \\
\hline ADWS04 & $\ldots$ & $r=0.61, P<0.0001$ & $r=0.34, P=0.0041$ & $r=0.52, P<0.0001$ & $r=0.47, P<0.0001$ \\
\hline ADWS05 & $\ldots$ & $\ldots$ & $r=0.32, P=0.0070$ & $r=0.57, P<0.0001$ & $r=0.36, P=0.002$ \\
\hline FRY04 & $\ldots$ & $\ldots$ & $\ldots$ & $r=0.45, P=0.0001$ & $r=0.45, P=0.0001$ \\
\hline FRY05 & $\ldots$ & $\ldots$ & $\ldots$ & $\ldots$ & $r=0.52, P<0.0001$ \\
\hline
\end{tabular}

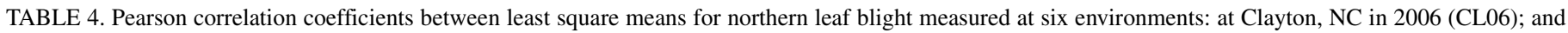
two environments in 2004 and one environment in each of 2005 and 2006 at Wooster, OH (FRY04, KING04, SHFTR05, SHFTR06, and OARDC07)

\begin{tabular}{|c|c|c|c|c|c|}
\hline Location & FRY04 & KING04 & OARDC07 & SHFTR05 & SHFTR06 \\
\hline CL06 & $r=0.21, P=0.0819$ & $r=0.38, P=0.0017$ & $r=0.49, P<0.0001$ & $r=0.35, P=0.0003$ & $r=0.31, P=0.0013$ \\
\hline FRY04 & $\ldots$ & $r=0.19, P=0.1193$ & $r=0.24, P=0.0463$ & $r=0.20, P=0.0961$ & $r=0.31, P=0.0084$ \\
\hline KING04 & $\ldots$ & $\ldots$ & $r=0.16, P=0.1881$ & $r=0.33, P=0.0061$ & $r=0.17, P=0.1494$ \\
\hline OARDC07 & $\ldots$ & $\ldots$ & $\ldots$ & $r=0.29, P=0.0027$ & $r=0.31, P=0.0012$ \\
\hline SHFTR05 & $\ldots$ & $\ldots$ & $\ldots$ & $\ldots$ & $r=0.56, P<0.0001$ \\
\hline
\end{tabular}


words, a longer time to anthesis was associated with higher resistance for all the diseases.

Linkage mapping. A linkage map was constructed using 871 molecular markers (SSR and SNP markers) covering a total map length of 1,697.3 cM. The average distance between mapped markers was $1.9 \mathrm{cM}$. The markers dupssr14 and PHM14046.9 on chromosome 8 bin 8.08 are inverted in the linkage map constructed in this study compared with the marker order reported in the intermated IBM reference map (IBM2 2005 Neighbors map). The construction of this map is further detailed in Coles et al. (25).

QTL mapping. QTL mapping, using LSM values derived from combined data over all environments for each disease and for GDDTA, detected 9 QTL for SLB; 8 for GLS; 6, with 1 QTLQTL interaction, for NLB (Table 6); and 10 for GDDTA.

Of the nine SLB QTL detected, the three that accounted for the largest amount of phenotypic variation were located in bins 3.04, 9.03 , and 10.05 , accounting for $26.0,9.0$, and $10.6 \%$, respectively. For GLS, the three QTL that accounted for the largest amount of phenotypic variation were located in bins 2.02-2.03, 7.02, and 10.05 , accounting for $11.2,9.9$, and $16.0 \%$ respectively. The three NLB QTL that accounted for the largest amount of phenotypic variation were located in bins 1.06, 8.02, and 8.05 and accounted for $18.7,12.8$, and $8.3 \%$, respectively. In each of these cases, with the exception of the GLS QTL in bin 8.07-8.09, resistance was conferred by the allele derived from Ki14. The largest-effect QTL for GDDTA were located in bins 3.04/3.05 and 10.03, accounting for 11.6 and $23 \%$ of the phenotypic variation, respectively.

Several QTL were associated with resistance to more than one disease. In bin 1.06, QTL for SLB, GLS, and NLB all colocalized at approximately the same map position $(<5 \mathrm{cM}$ difference between the QTL peaks for the three diseases). QTL for SLB and GLS resistance colocalized in bins 1.08-1.09, 3.04, and 10.05. One QTL in bin 8.05 colocalized for SLB and NLB resistance and one QTL in bin 2.02-2.03 colocalized for GLS and NLB resistance. For our purposes, QTL were considered colocalized if they were within $20 \mathrm{cM}$ of each other $(19,51,77)$. QTL for GDDTA were also identified at four of these six loci (bins 1.06, 3.04/3.05, 8.05 and 10.05). However, no disease resistance QTL were identified at the largest-effect GDDTA QTL at bin 10.03.

\section{DISCUSSION}

The significant correlations between resistances and the three diseases assessed (SLB, GLS, and NLB) (Table 5) were observed, and the six QTL associated with resistance to two or more

TABLE 6. Chromosomal location in centimorgans (cM) and parameters associated with quantitative trait loci (QTL) detected in the 109 Ki14 $\times$ B73 recombinant inbred lines (KB population) for resistance to southern leaf blight (SLB), gray leaf spot (GLS), and northern leaf blight (NLB) and for growing degree days to anthesis (GDDTA) over all environments in which each trait was measured ${ }^{\mathrm{a}}$

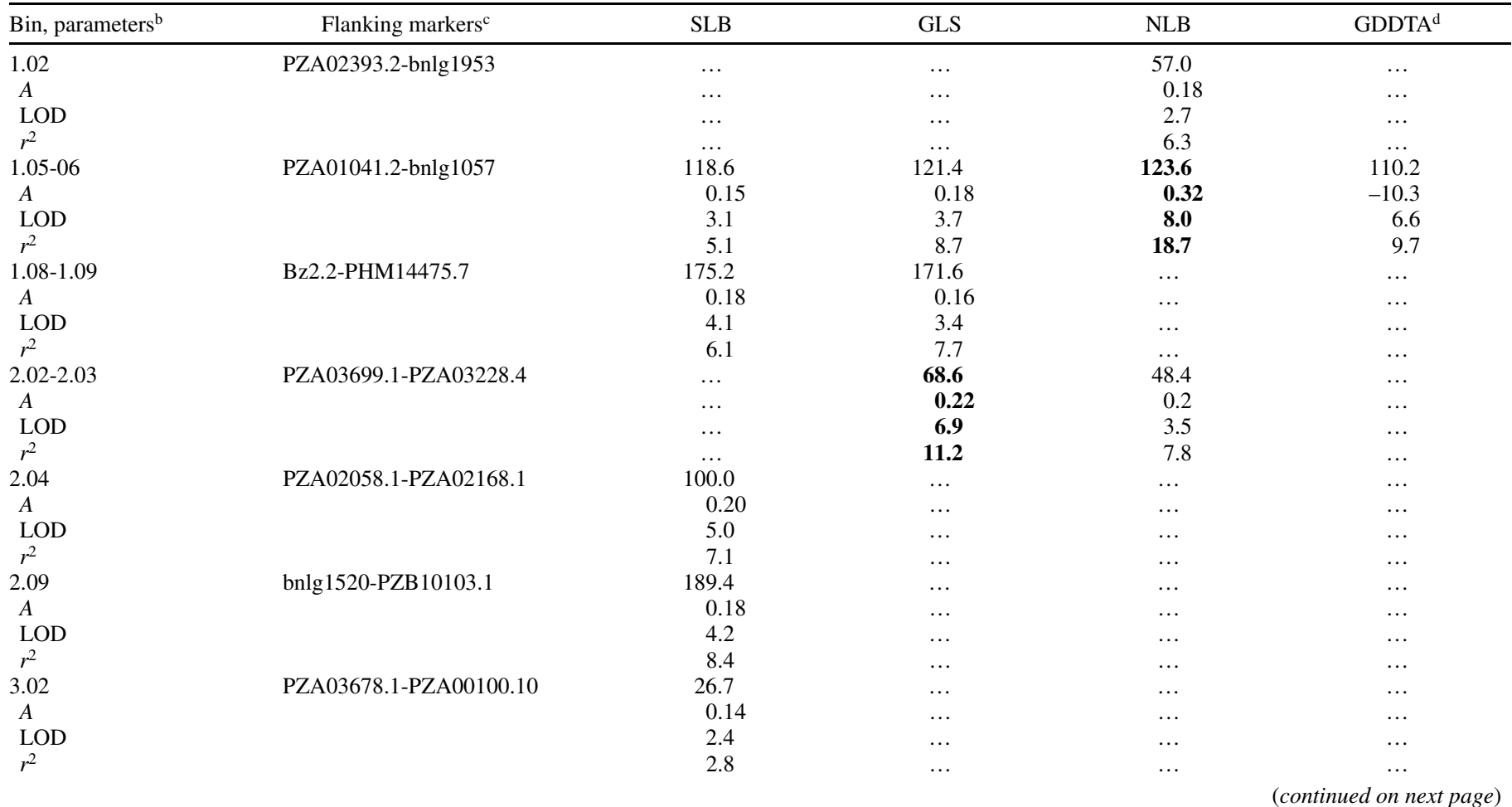

${ }^{a}$ SLB field trials were performed at Clayton, NC in 2004, 2005, and 2006; Tifton, GA in 2005; and Wooster, OH in 2004. GLS field trials were performed in Salisbury, NC in 2006; Andrews, NC in 2004 and 2005; and at two environments in 2004 and one environment in 2005 at Wooster, OH. Field trials for NLB were performed at Clayton, NC in 2006 and two environments in 2004 and one environment in each of 2005 and 2006 at Wooster. GDDTA was measured in the SLB 2004, 2005, and 2006 trials and in the GLS 2005 trial in Andrews, NC.

${ }^{\mathrm{b}}$ Chromosome bin location of QTL peak on one of the 10 chromosomes of the maize genome. Bins divide the genetic map into 100 approximately equal segments. The segments are designated with the chromosome number followed by a two digit decimal (e.g., 1.00, 1.01, 1.02, and so on). The marker order determined for the population used in this experiment largely follows the marker order shown in the standard maize genetic map (the B73 $\times$ Mo17 map). Numbers following the bin number indicate chromosomal position of the predicted QTL in centimorgans (cM). A = additive effect of the QTL. A positive number indicates that the allele for resistance or for fewer GDDTA was derived from Ki14. A negative number indicates that the allele for resistance or fewer GDDTA was derived from B73. LOD = logarithm-of-odds value at the position of peak likelihood of the QTL and $r^{2}$ estimates the proportion of phenotypic variance (percentage) explained by the QTL. QTL with $r^{2}>10 \%$ are indicated in bold.

${ }^{\mathrm{c}}$ Markers flanking the QTL peak positions.

${ }^{\mathrm{d}}$ GDDTA explaining $<5 \%$ of the variation and not colocalizing with any disease resistance QTL are not shown for space considerations.

e QTL interactions. Type of QTL interaction (AA) identified and determined by QTL Cartographer (AA is an additive-additive interaction).

${ }^{f} R^{2}$ estimates the proportion of phenotypic variance (percentage) explained by the full model (all of the detected QTL) for each of the three diseases. 
diseases (Table 6) would seem to provide good evidence that MDR loci, either carrying a single gene conferring resistance to two or more diseases or two closely linked genes conferring disease-specific resistances to different diseases, are segregating in the KB population. However, significant correlations between resistance and each disease and GDDTA were also observed, and four of the six putative MDR loci also had an effect on GDDTA. Furthermore, in each of these four cases, the Ki14 allele conferred both later maturity and increased disease resistance. This is what would be expected if the MDR was derived from an effect on maturity rather than on disease resistance itself. Of the remaining two putative MDR loci that did not colocalize with GDDTA QTL in bins 1.08/1.09 and 2.02/2.03 (Table 6), the former comprises SLB and NLB QTL that are $20 \mathrm{cM}$ apart-the arbitrarily chosen maximum distance used here for declaring colocalizing QTL. Although QTL mapping with a relatively small population is imprecise, it is somewhat unlikely that the same gene would underlie QTL $20 \mathrm{cM}$ apart.

All three of the diseases assessed here are substantially necrotrophic diseases that tend to progress most rapidly after anthesis, when resources start to be directed toward grain fill rather than growth and defense. Therefore, it would seem that a significant proportion of the observed correlation between disease resistances may be due to the common effect of variation in maturity on resistance to the different diseases. It should be noted that the association between flowering time and disease resistance, while strong, is not absolute. The largest flowering time QTL in bin 10.03 , explaining $23 \%$ of the variation in this trait, was not associated with resistance to any of the diseases assessed. It is also worth noting that the largest-effect QTL for both SLB and GLS in bins 2.02-2.03 and 3.04, respectively, are not within $20 \mathrm{cM}$ of any flowering time QTL but are also relatively distant from other disease resistance QTL (20 and $15 \mathrm{cM}$ distant, respectively).

A consistent, though generally relatively low, association between disease resistance and time to maturity has been observed in a number of recent mapping studies and meta-analyses (3$8,13,24,81,83)$. In a series of studies mapping QTL for resistance to SLB, GLS, and NLB in the widely used maize IBM population, pairwise correlations between resistances to the different diseases and between resistance to each disease and time to flowering were all significant but were substantially lower than those observed in this study $(5,6,8)$. Furthermore, in these studies, only a single QTL was identified that conferred resistance to more than one disease; a QTL in bin 2.04 that was associated with resistance to both SLB and GLS. The parents of the IBM population, B73 and Mo17, are both temperate inbreds and flower at approximately the same time under a variety of conditions. The parents of the $\mathrm{Kb}$ population, Ki14 and B73, are tropical and temperate inbreds, respectively, and B73 flowers $\approx 2$ to 3 weeks

TABLE 6. (continued from preceding page)

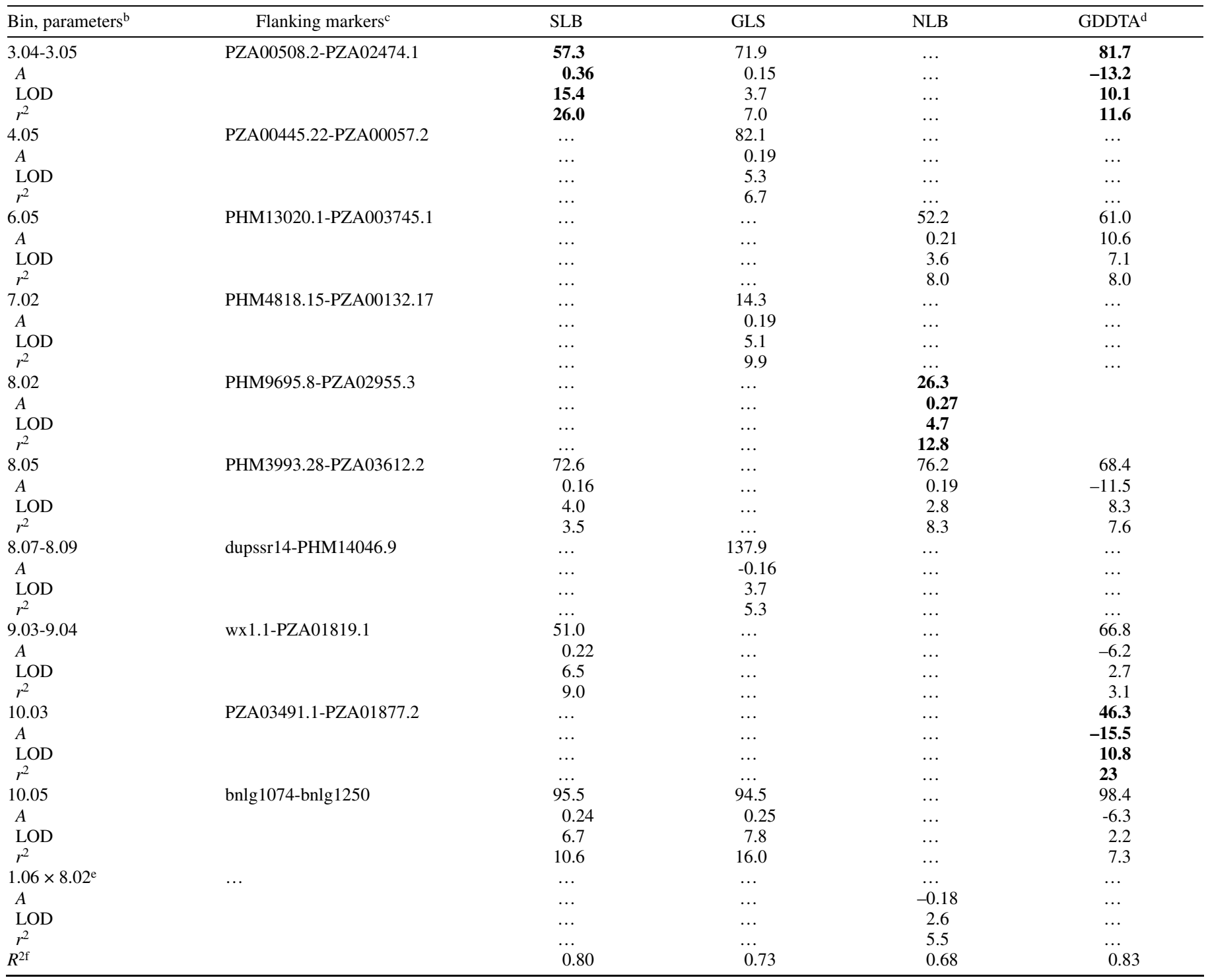


earlier than Ki14 in the summer in NC. Therefore, the fact that flowering time had little association with disease resistance in the IBM population is likely a consequence of the relatively small amount of variation for this trait in the IBM population compared with the KB population. It should also be noted that the relatively small population size used in this study likely resulted in failure to detect some QTL, particularly those with relatively small effects, as well as possible overestimation of the effects of those QTL detected $(9,65)$.

Most of the SLB QTL identified in the current study (Table 6) colocalize with SLB QTL identified previously in other populations $(3-6,12,21,39,87)$. In particular, the large-effect SLB QTL identified in bin 3.04 colocalized with the largest-effect QTL identified in most of these previous studies. Several QTL for resistance to other diseases and major virus disease resistance genes have also been identified in this region (83). The GLS QTL in bin 1.06 is of particular interest because it colocalized with QTL identified for SLB and NLB in this study and, furthermore, large-effect GLS QTL have been detected in this region in several other studies with different populations $(13,24,44,64)$. However, flowering time was measured in only one of these studies (13) and, in that case, as in the present study, an association was observed between the 1.06 region and flowering time. Four of the six NLB QTL identified in the current study, in bins 1.06, 2.02$2.03,6.05$, and 8.02, colocalized with previously reported NLB resistance QTL (80). None of the sources of resistance are shared between this study and these previous studies.

Our initial hypothesis was that, because the causal organisms of the three diseases assessed share certain aspects of their pathogenesis processes, one might expect to find MDR QTL that affected these shared aspects. Based on this study as well as our previous work $(5,6,8)$, this has not been borne out. Our unpublished work as well as the previous findings suggest that MDR QTL likely exist, though they may be QTL of relatively small effect-possibly below the level of detection in these studies. In the cases we have studied, the larger-effect QTL tend to be disease specific. Furthermore, these results emphasize the fact that, when MDR QTL are identified, one must be aware that they may be confounded with the pleiotropic effects of loci affecting maturity.

\section{ACKNOWLEDGMENTS}

This work was funded by the United States Department of AgricultureAgricultural Research Service and by a grant from the CGIAR Generation Challenge Program (project no. 8). We thank M. Casey, D. Rhyne, R. Wisser, D. Stephens, K. Guill, R. Nelson, and K. Simcox for their help with various aspects of the research. We would like to dedicate this article to the memory of Donna Stephens.

\section{LITERATURE CITED}

1. Ayers, J. E., Nelson, R. R., Castor, L. L., and Blanco, M. H.1976. Yield losses in corn caused by Helminthosporium maydis race T. Plant Dis. Rep. 60:331-335.

2. Baker, R. 1984. Some of the open pollinated varieties that contributed the most to modern hybrid corn. Illinois Corn Breeder's School Proc. 20:1-19.

3. Balint-Kurti, P. J., and. Carson, M. L.2006. Analysis of quantitative trait loci for resistance to southern leaf blight in juvenile maize. Phytopathology 96:221-225.

4. Balint-Kurti, P. J., Krakowsky, M. D., Jines, M. P., Robertson, L. A., Molnár, T. L., Goodman, M. M., and Holland, J. B. 2006. Identification of quantitative trait loci for resistance to southern leaf blight and days to anthesis in a maize recombinant inbred line population. Phytopathology 96:1067-1071.

5. Balint-Kurti, P., Wisser, R. J., and J. Zwonitzer. 2008b. Use of the IBM population for precise mapping of quantitative trait loci for gray leaf spot resistance in maize. Crop Sci. 48:1696-1704.

6. Balint-Kurti, P. J., Yang, J., Esbroeck, G. V., Jung, J., and Smith, M. E. Use of a maize advanced intercross line population for mapping of quantitative trait loci for northern leaf blight resistance and for the investigation of multiple disease resistance. Crop Sci. (In press.)
7. Balint-Kurti, P. J., Zwonitzer, J. C., Pè, M. E., Pea, G., Lee, M., and Cardinal, A. J. 2008. Identification of quantitative trait loci for resistance to southern leaf blight and days to anthesis in two maize recombinant inbred line populations. Phytopathology 98:315-320.

8. Balint-Kurti, P. J., Zwonitzer, J. C., Wisser, R. J., Carson, M. L., OropezaRosas, M., Holland, J. B., and Szalma, S. J. 2007. Precise mapping of quantitative trait loci for resistance to southern leaf blight, caused by Cochliobolus heterostrophus race $\mathrm{O}$, and flowering time using advanced intercross maize lines. Genetics 176:645-657.

9. Beavis, W. D., Smith, O. S., Grant, D., and Fincher, R.. 1994. Identification of quantitative trait loci using a small sample of topcrossed and F-4 progeny from maize. Crop Sci. 34:882-896.

10. Beckman, P. M., and Payne, G. A. 1982. External growth, penetration, and development of Cercospora zeae maydis in corn leaves. Phytopathology 72:810-815.

11. Bent, A. F., and Mackey, D. 2007. Elicitors, effectors, and $R$ genes: The new paradigm and a lifetime supply of questions. Annu. Rev. Phytopathol. 45:399-436.

12. Bubeck, D. M. 1991. Molecular and biometric evaluation of gray leaf spot and southern corn leaf blight resistance in maize. Ph.D. thesis, Department of Crop Science. North Carolina State University, Raleigh.

13. Bubeck, D. M., Goodman, M. M., Beavis, W. D., and Grant, D. 1993. Quantitative trait loci controlling resistance to gray leaf spot in maize. Crop Sci. 33:838-847.

14. Burnette, D. C., and White, D. G. 1985. Inheritance of resistance to Bipolaris maydis race $\mathrm{O}$ in crosses derived from nine resistant inbred lines of maize Phytopathology 75:1195-1200.

15. Byrnes, K. J., Pataky, J. K., and White, D. G. 1989. Relationships between yield of three maize hybrids and severity of Southern leaf blight caused by race $\mathrm{O}$ of Bipolaris maydis. Plant Dis. 73:834-840.

16. Campbell, C. L., and Madden, L. V. 1990. Temporal analysis of epidemics. I: descriptions and comparisons of disease progress curve. Pages 161-202 in: Introduction to Plant Disease Epidemiology. Wiley, New York.

17. Cao, H., Glazebrook, J., Clarke, J. D., Volko, S., and Dong, X. 1997. The Arabidopsis NPR1 gene that controls systemic acquired resistance encodes a novel protein containing ankyrin repeats. Cell 88:57-63.

18. Cao, H., Li, X., and Dong, X. 1998. Generation of broad-spectrum disease resistance by over-expression of an essential regulatory gene in systemic acquired resistance. Proc. Natl. Acad. Sci. USA 95:6531-6536.

19. Cardinal, A. J., and Lee, M. 2005. Genetic relationships between resistance to stalk-tunneling by the European corn borer and cell-wall components in maize population B73×B52. Theor. Appl. Genet. 111:1-7.

20. Carson, M. L. 1998. Aggressiveness and perennation of isolates of Cochliobolus heterostrophus from North Carolina. Plant Dis. 82:1043-1047.

21. Carson, M. L., Stuber, C. W., and Senior, M. L. 2004. Identification and mapping of quantitative trait loci conditioning resistance to southern leaf blight of maize caused by Cochliobolus heterostrophus race O. Phytopathology 94:862-867.

22. Ceballos, H., Deutsch, J. A., and Gutierrez, H. 1991. Recurrent selection for resistance to Exserohilum turcicum in eight subtropical maize populations. Crop Sci. 31:964-971.

23. Century, K. S., Shapiro, A. D., Repetti, P. P., Dahlbeck, D., Holub, E., and Staskawicz, B. J 1997. NDR1, a pathogen-induced component required for Arabidopsis disease resistance. Science 278:1963-1965.

24. Clements, M. J., Dudley, J. W., and White, D. G. 2000. Quantitative trait loci associated with resistance to gray leaf spot of corn. Phytopathology 90:1018-1025.

25. Coles, N. D. 2009 The Genetic architecture of maize photoperiod sensitivity revealed by recombinant inbred line, backcross, and heterogeneous inbred family populations. Ph.D. thesis, Department of Crop Science, North Carolina State University, Raleigh.

26. Darrah, L. L., and Zuber, M. S. 1986. 1985 United States farm maize germplasm base and commercial breeding strategies. Crop Sci. 26:1109-1113.

27. Fan, J.-B., Oliphant, A., Shen, R., Kermani, B. G., Garcia, F., Gunderson, K. L. , Hansen, M., Steemers, F., Bulter, S. L., Deloukas, P., Galver, L., Hunt, S., McBride, C., Bibikova, M., Rubano, T., Chen, J., Wickham, E., Doucet, D., Chang, W., Campbell, D., Zhang, B., Kruglyak, S., Bentley, D., Haas, J., Rigault, P., Zhou, L., Stuelpnagel J., and Chee, M. S. 2003. Highly parallel SNP genotyping. Cold Spring Harbor Symp. Quant. Biol. 68:69-78.

28. Fisher, D. E., Hooker, A. L., Lim, S. M., and Smith, D. R. 1976. Leaf infection and yield loss caused by 4 Helminthosporium leaf diseases of corn. Phytopathology 66:942-944.

29. Geiger, H. H., and Heun, M. 1989. Genetics of quantitative resistance to fungal diseases. Annu. Rev. Phytopathol. 27:317-341.

30. Gordon, S. G., Lipps, P. E., and Pratt, R. C. 2006. Heritability and components of resistance to Cercospora zeae-maydis derived from maize inbred V0613Y. Phytopathology 96:593-598.

31. Hakiza, J. J., Lipps, P. E., St. Martin, S., and Pratt, R. C. 2004. Heritability and number of genes controlling partial resistance to Exserohilum turcicum in maize inbred H99. Maydica 49:173-182. 
32. Hallauer, A. R., Russell, W. A., and Smith, O. S. 1983. Quantitative analysis of Iowa Stiff Stalk Synthetic. In: Stadler Genet. Symp. St. Louis. J. P. Gustafsen, ed. Univ. Mo. Agric. Exp. Stn. Columbia.

33. Holland, J. B., W. E. Nyquist, and C. T. Cervantes-Martinez 2003. Estimating and interpreting heritability for plant breeding: an update. Plant Breed. Rev. 22:9-112.

34. Holley, R. N., and Goodman, M. M. 1989. New sources of resistance to southern corn leaf blight from tropical hybrid maize derivatives. Plant Dis. 73:562-564.

35. Hooker, A. L., Smith, D. R. Lim, S. M., and Beckett, J. B. 1970. Reaction of corn seedlings with male-sterile cytoplasm to Helminthosporium maydis. Plant Dis. Rep. 54:708-712.

36. Hooker, A. L., Smith, S. D. R., Lim, M., and Musson, M. D. 1970. Physiological races of Helminthosporium maydis and disease resistance. Plant Dis. Rep. 54:1109-1110.

37. Huff, C. A., Ayers, J. E., and Hill, R. R. 1988. Inheritance of resistance in corn (Zea mays) to gray leaf spot. Phytopathology 78:790-794.

38. Jennings, P. R., and Ulstrup, A. J. 1957. A histological study of three Helminthosporium leaf blights of corn. Phytopathology 47:707-714.

39. Jiang, J. C., Edmeades, G. O., Armstead, I., Lafitte, H. R., Hayward, M. D., and Hoisington, D. 1999. Genetic analysis of adaptation differences between highland and lowland tropical maize using molecular markers. Theor. Appl. Genet. 99:1106-1119.

40. Kelly, J. D., and Vallejo, V. 2006. QTL analysis of multigenic disease resistance in plant breeding. Pages 21-48 in: Multigenic and Induced Systemic Resistance in Plants. Tuzun and Bent, eds. Springer Science, New York.

41. Lander, E. S., Green, P., Abrahamson, J., Barlow, A., Daly, M. J., Lincoln, S. E., and Newburg, L. 1987. MAPMAKER: an interactive computer package for constructing primary genetic linkage maps of experimental and natural populations. Genomics 1:174-181.

42. Latterell, F. M., and Rossi, A. E. 1983. Gray leaf spot of corn: a disease on the move. Plant Dis. 67:842-847.

43. Lee, M., Sharopova, N., Beavis, W. D., Grant, D., Katt, M., Blair, D., and Hallauer, A. 2002. Expanding the genetic map of maize with the intermated B73 × Mo17 (IBM) population. Plant Mol. Biol. 48:453-461.

44. Lehmensiek, A., Esterhuizen, A.-M., van-Staden, D., Nelson, S.-W., and Retief, A.-E. 2001. Genetic mapping of gray leaf spot (GLS) resistance genes in maize. Theor. Appl. Genet. 103:797-803.

45. Levy, Y., and Cohen, Y. 1983. Biotic and environmental factors affecting infection of sweet corn with Exserohilum turcicum. Phytopathology 73:722-725.

46. Lim, S. M. 1975. Heterotic effects of resistance in maize to Helminthosporium maydis race O. Phytopathology 65:1117-1120.

47. Lim, S. M., and Hooker, A. L. 1976. Estimates of combining ability for resistance to Helminthosporium maydis race $\mathrm{O}$ in a maize population. Maydica 21:121-128.

48. Lincoln, S. E., Daly, M. J., and Lander, E. S. 1992. Constructing genetic maps with MAPMAKER/EXP 3.0. In: Whitehead Institute Technical Report, 3rd ed. The Whitehead Institute, Cambridge, MA.

49. Lipps, P. E., White, D. G., Ayers, J. E., and Dunkle, L. D. 1998. Gray leaf spot of corn: update. A report from NCR-25 technical committee on corn and sorghum diseases. The American Phytopathological Society. Published Online www.apsnet.org/online/feature/grayleaf/fullrprt.htm

50. McMaster, G. S., and Wilhelm, W. W. 1997. Growing degree-days: One equation, two interpretations. Agric. For. Meteorol. 87:291-300.

51. Melchinger, A. E., Utz, H. F., and Schön, C. C. 1998. Quantitative trait locus (QTL) mapping using different testers and independent population samples in maize reveals low power of QTL detection and large bias in estimates of QTL effects. Genetics 149:383-403.

52. Mikel, M. A., and Dudley, J. W. 2006. Evolution of North American dent corn from public to proprietary germplasm. Crop Sci. 46:1193-1205.

53. Mitchell-Olds, T., James, R. V., Palmer, M. J., and Williams, P. H. 1995. Genetics of Brassica rapa (syn. campestris). 2. Multiple disease resistance to three fungal pathogens: Peronospora parasitica, Albugo candida, and Leptosphaeria maculans. Heredity 75:362-369.

54. Nurmberg, P. L., Knox, K. A., Yun, B.-W., Morris, P. C., Shafiei, R., Hudson, A., and Loake, G. J. 2007. The developmental selector AS1 is an evoluationarily conserved regulator of the plant immune response. Proc. Natl. Acad. Sci. USA 104:18795-18800.

55. Pate, J. B., and Harvey, P. H. 1954. Studies on the inheritance of resistance in corn to Helminthosporium maydis leaf spot. Agron. J. 46:442-445.

56. Payne, G. A., Duncan, H. E., and Adkins, C. R. 1987. Influence of tillage on development of gray leaf spot and number of airborne conidia of Cercospora zeae-maydis. Plant Dis. 71:329-332.

57. Payne, G. A., and Waldron, J. K. 1983. Overwintering and spore release of Cercospora zeae-maydis in corn debris in North Carolina. Plant Dis. 67:87-89.

58. Piepho, H. P., and Gauch, Jr., H. G. 2001. Marker pair selection for mapping quantitative trait loci. Genetics 157:433-444.

59. Raymundo, A. D., and Hooker, A. L. 1981. Measuring the relationship between northern corn leaf blight and yield losses. Plant Dis. 65:325-327.
60. Robertson-Hoyt, L. A., Jines, M. P., Balint-Kurti, P. J., Kleinschmidt, C. E., White, D. G., Payne, G. A., Maragos, C. M., Molnár, T. L., and Holland, J. B. 2006. QTL mapping for Fusarium ear rot and fumonisin contamination resistance in two maize populations. Crop Sci. 46:1734-1743.

61. Ross, H. 1986. Potato breeding. Problems and perspectives. Adv. Plant Breed. (Suppl.) 13:5-68.

62. Russell, W. A. 1972. Registration of B70 and B73 parental lines of maize. Crop Sci. 12:721.

63. Saghai-Maroof, M. A., Soliman, K. M., Jorgenson, R., and Allard, R. W. 1984. Ribosomal DNA spacer-length polymorphisms in barley: Mendelian inheritance, chromosomal location, and population dynamics. Proc. Natl. Acad. Sci. USA 81:8014-8018.

64. Saghai Maroof, M. A., Yue, Y. G., Xiang, Z. X., Stromberg, E. L., and Rufener, G. K. 1996. Identification of quantitative trait loci controlling resistance to gray leaf spot disease in maize. Theor. Appl. Genet. 93:539-546.

65. Schon, C. C., Utz, H. F., Groh, S., Truberg, B., Openshaw, S., and Melchinger, A. E. 2004. Quantitative trait locus mapping based on resampling in a vast maize testcross experiment and its relevance to quantitative genetics for complex traits. Genetics 167:485-498.

66. Senior, M. L., Murphy, J. P., Goodman, M. M., and Stuber, C. W. 1998. Utility of SSRs for determining genetic similarities and relationships in maize using an agarose gel system. Crop Sci. 38:1088-1098.

67. Setboonsarng, S. 1990. Biotechnology and developing country agriculture: Maize in Thailand. Tech. Pap. OECD Dev. Cent. 20:71.

68. Shaner, G., and Finney, P. E. 1977. The effect of nitrogen fertilizer on expression of slow mildewing resistance in Knox wheat. Phytopathology 67:1051-1056.

69. Sriwatanapongse, S., Jinahyon, S., and Vasal, S. 1993. Suwan-1: Maize from Thailand to the World. Centro Internacional de Mejoramiento de Maiz, Chapingo, Mexico.

70. Tefferi, A., Hulluka, M., and Welz, H. G. 1996. Assessment of damage and grain yield loss in maize caused by northern leaf blight in western Ethiopia. J. Plant Dis. Prot. 103:353-363.

71. Thompson, D. L., and Bergquist, R. R. 1984. Inheritance of mature plant resistance to Helminthosporium maydis race $\mathrm{O}$ in maize. Crop Sci. 24:807-811.

72. Thompson, D. L., Bergquist, R. R., Payne, G. A., Bowman, D. T., and Goodman, M. M. 1987. Inheritance of resistance to gray leaf spot in maize. Crop Sci. 27:243-246.

73. Troyer, A. F. 1999. Background of U.S. hybrid corn. Crop Sci. 39:601-626.

74. Vadasz, C., Saito, M., Gyetvai, B. M., Oros, M., Szakall, I. , Kovacs, K. M., Prasad, V. V. T. S., Morahan, G., and Toth, R. 2007. Mapping of QTLs for oral alcohol self-administration in B6.C and B6.I quasi-Congenic RQI strains. Neurochem. Res. 32:1099-1112.

75. Van der Plank, J. E. 1963. Plant Diseases: Epidemics and Control. Academic Press., New York.

76. Van Ooijen, J. W., and Voorrips, R. E. 2001. JoinMap 3.0, Software for the calculation of genetic linkage maps. Plant Research International, Wageningen, The Netherlands.

77. Visscher, P. M., Thompson, R., and Haley, C. S. 1996. Confidence intervals in QTL mapping by bootstrapping. Genetics 143:1013-1020.

78. Wang, S., Basten, C. J., and Zeng, Z.-B. 2007. Windows QTL Cartographer 2.5. Available online: http://statgen.ncsu.edu/qtlcart/WQTLCart.htm. Department of Statistics, North Carolina State University, Raleigh.

79. Ward, J. M. J., Stromberg, E. L., Nowell, D. C., and Nutter, F. W., Jr. 1999. Gray leaf spot: a disease of global importance in maize production. Plant Dis. 83:884-895.

80. Welz, H. G., and Geiger, H. H. 2000. Genes for resistance to northern corn leaf blight in diverse maize populations. Plant Breed. 119:1-14.

81. Welz, H. G., Schechert, A. W., and Geiger., H. H. 1999. Dynamic gene action at QTLs for resistance to Setosphaeria turcica in maize. Theor. Appl. Genet. 98:1036-1045.

82. White, D. G., ed. 1999. Compendium of Corn Diseases, 3rd ed. The American Phytopathological Society, St. Paul, MN

83. Wisser, R. J., Balint-Kurti, P. J., and Nelson, R. J. 2006. The genetic architecture of disease resistance in maize: a synthesis of published studies. Phytopathology 96:120-129.

84. Wisser, R. J., Sun, Q., Hulbert, S. H., Kresovich, S., and Nelson, R. J. 2005. Identification and characterization of regions of the rice genome associated with broad-spectrum, quantitative disease resistance. Genetics 169:2277-2293.

85. Young, N. D. 1996. QTL mapping and quantitative disease resistance in plants. Annu. Rev. Phytopathol. 34:479-501.

86. Zeng, Z.-B., Kao, C.-H., and Basten, C. J. 1999. Estimating the genetic architecture of quantitative traits. Genet. Res. 74:279-289.

87. Zwonitzer, J. C., Bubeck, D. M., Bhattramakki, D., Goodman, M. M., Arellano, C., and Balint-Kurti, P. J. 2008. Use of selection with recurrent backcrossing and QTL mapping to identify loci contributing to southern leaf blight resistance in a highly resistant maize line. Theor. Appl. Genet. 118:911-925. 